\title{
Windowless Airplanes: A boon to air transportation
}

\author{
Alisha Nagpal ${ }^{1}$, Lakshay Rohilla ${ }^{1}$, Inderpeet Kaur ${ }^{1}$, Sanchit \\ Sharma $^{2}$ \\ ${ }^{1}$ Department of Electronics and Communications, Chitkara University, Punjab, India \\ ${ }^{2}$ Chandigarh College of Engineering and Technology, Chandigarh, India \\ alishanagpa184@gmail.com, bassist.lakshay@gmail.com, inderpreet_95@yahoo.com, \\ sanchit2794@gmail.com,
}

\begin{abstract}
This document describes the complete technology and the features included in the concept of windowless airplanes. The concept has been originated in order to revolutionize the market of air transportation besides, achieving the various sustainable advantages of weight reduction, low emission of $\mathrm{CO}_{2}$, increased fuel efficiency and low operational cost. The technology aims to provide better panoramic view to passengers through organic led displays though the plane is not less than a cargo plane in surface looks.
\end{abstract}

Keywords: Windowless airplanes, organic led displays, cost efficient, avatar, passenger tracking, fuel efficient, light weight planes.

\section{Introduction}

The concept of windowless airplanes has been introduced with a hope of providing better view at $35000 \mathrm{ft}$ height and facilitating sustainable development. The windows have been thought of substitution with the organic LED's displays all over. The displays will be flood with the panoramic view of surroundings being captured by cameras attached on the exterior of the fuselage. The innovation is to enable passengers to surf high speed interneton-board. It will be even providing the preference of video conferencing at a height of $35000 \mathrm{ft}$. Many more features have been added up in order to make the coming product, a complete package.

\section{Detailed Working \& Description}

\subsection{Windows Substitution}

The fuselage of windowless airplanes would be having no windows and it will be lined with thin organic led display panels that could display surrounding vistas, wallpapers or work presentations [1]. These screen panels are highly flexible, strong and provides HD display. Organic led's are better than inorganic LEDs in every context including high efficiency, light weight, no backlight requirement, high definition quality and so on. The 
input to these screen panels would be the serene view of atmosphere which is around $35000 \mathrm{ft}$ above the Earth's surface. The view will be captured by the cameras positioned outwardly on the fuselage. These screens are adjustable in size and would be present on the back of seats as well as on the entire fuselage as shown in fig.1. The change of screen contents can be gesture driven or touch sensing depending upon the preferences of the user [5].

\subsection{Attractive Digital Wallpapers}

In order to make passengers feel free from any kind of discrepancy like queasiness, motion sickness or acrophobia at a larger heights, the option of switching the screen displays with any digital wallpaper already present in the memory of screen driving unit can be implemented with the intention of feeling unpretentious atmosphere[6].

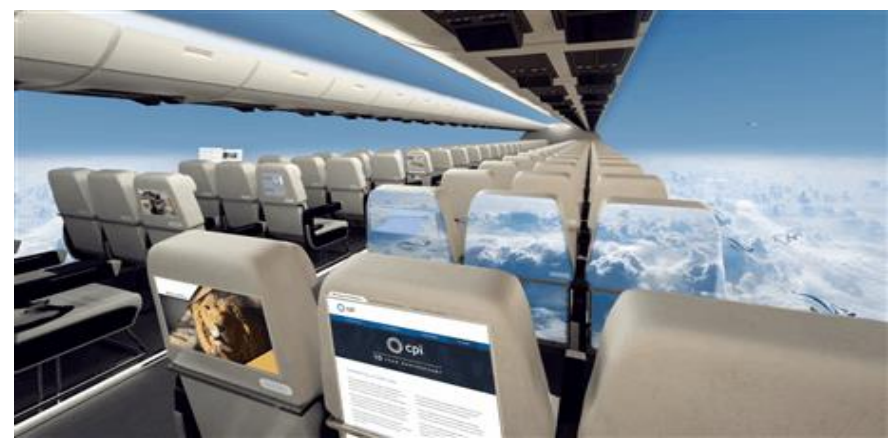

Fig.1: Thin lining of screens on fuselage as well as on back of seats [1]

\subsection{Multiple Screen Displays}

In order to avoid the conflict of display priority among the passengers, the feature of multiple screen displays will act as a tonic. Multiple screen display would be made possible due to the parallax barrier technology according to which both human eyes would be projected to two different stereoscopic images that can be made possible by the presence of barriers between the screen and human eyes. In this case two screens will be visible to both the eyes as $3 \mathrm{~d}$ images as shown in fig.2. This feature allows the passengers to maintain the integrity of their privacies and choices [7].

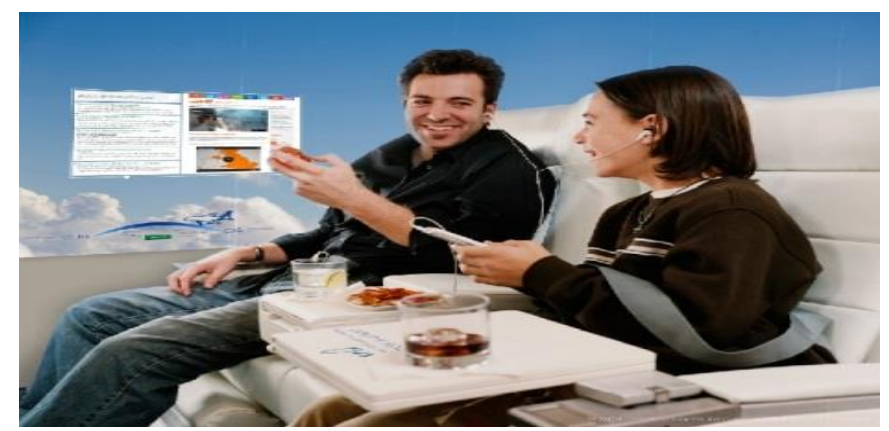

Fig.2: Multiple screen displays using parallax barrier technology [5] 


\subsection{High Speed Internet}

More entertainment opportunities through high speed internet are determined in the technology. The internet will be processed at such a pace that non-interrupted video conferences can even be provided at a height of more than $35000 \mathrm{ft}$ above sea level. The idea revolves around the formation of separate Pico cells on board and exterior antennas on surface. Pico cell is the smaller, low cost independent cell station that connects to the BSC (Base Station Controller). The airplane will have its own Pico cell which will connect to base station from where the data will be sent to the commercial satellites. In this way, high speed internet facilities can be operated at such heights even without inducing high international roaming charges [9].

\subsection{Passenger tracking and Personalized Avatar}

Passenger can be tracked anywhere on board using wireless sensor networks and the idea of personalized avatar is also introduced with the aim of providing personal guide right all the way through the plane. This will be made possible again using space sensors which are generally, the combination of three axis gyroscopes, compass sensors and accelerometers. The 1:1 full body tracking avatar technology is generally used in gaming zones but here only a symbolic representation will be used for cutting down the sensor prices. Most famous space sensor used for the same purpose is Yei's space sensor [3].

\subsection{Amorphous Solar Panels}

The outer surface of plane is bombarded with amorphous solar panels for contributing in driving electrical load of plane as well as low voltage devices on board like LED lights used for reading articles, magazines or any stuff during night mode in the plane. Basic idea is to minimize the load over the main power source installed in the plane [8].

\section{Advantages}

Any technology can be made adaptable only due to certain advantages. It has been said that whatever new could have been invented is already being in action. So, upcoming technologies are not new but their implications and effects to the environment are always fresh and innovative. The modernization lies only under making these effects sustainable so that technology can be welcomed whole heartedly without providing any sort of trade off or compromise. With this goal, windowless airplanes pass some tests based on its following enlisted advantages:

\subsection{Weight Reduction}

Cargo planes are always made as light as possible so that they can be able to lift maximum amount of commodities. For this reason only, cargo planes are never fitted with windows as there is no one inside to enjoy the nature's vista. As shown in table 1.1, although density of Plexiglas is less than that of aluminum but weight of aluminum in overall layer spread over 1 square foot of area is 2.5 times less than that of Plexiglas over the same amount of area. For all other materials that can be utilized in the place of windows, the density is more than that of aluminum and thus, justifies the elimination of windows. 
TABLE 1.1: Comparison of weights of different elements

\begin{tabular}{|c|c|c|c|}
\hline Element & \multicolumn{3}{|c|}{ Properties } \\
\hline & $\begin{array}{r}\text { Density } \\
\left.\mathrm{cm}^{3}\right)\end{array}$ & \begin{tabular}{|l|l}
$/$ & $\begin{array}{l}\text { Minimum } \\
\text { Thickness } \\
(\text { cm })\end{array}$ \\
\end{tabular} & $\begin{array}{l}\text { Weight to cover } 1 \\
\text { square foot area } \\
\left(930 \mathrm{~cm}^{2}\right)(\mathrm{g})\end{array}$ \\
\hline Aluminium & 2.7 & 0.1 & 251 \\
\hline Plexiglass & 1.18 & 0.6 & 658 \\
\hline Glass & $2.4-2.8$ & 0.4 & 892-1041 \\
\hline Silica & 2.2 & 0.32 & 654 \\
\hline Carbon & 3.71 & $0.2-0.4$ & 1725 \\
\hline
\end{tabular}

\subsection{Fuel efficient}

As there is a reduction in weight, so there is increase in fuel efficiency. Although the difference is not very wide, but by following more light weight substrates in future can lead to more fuel efficiency.

\subsection{Low operational and maintenance cost}

The adoption of new technology always comes with the fact of its shelf life. The predicted and calculated shelf life of screen panels and all space sensors is 10 years that deploys low maintenance cost and that too after the regular interval of 10 years. As shown in fig.3, the approach aims to cut down the operational and maintenance cost of airlines by 30 percent.

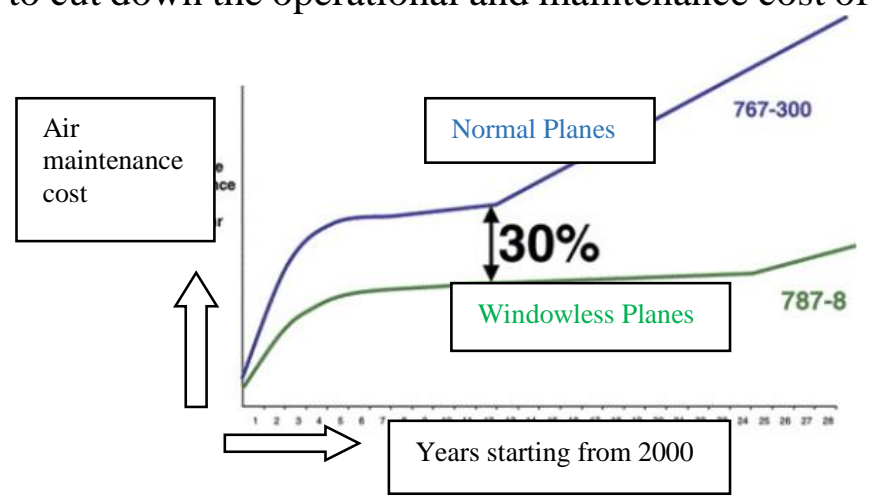

Fig.3: Graph of decrement in cost of air maintenance [8]

\subsection{Simplified construction}

For deploying windows, the area surrounding the windows should be strengthened up in order to tolerate the air thrust at greater heights above sea level. With removal of windows, these efforts are reduced and requirement of maximum strength is achieved at simplified construction only. 


\subsection{Low emission of $\mathrm{CO} 2$ molecules}

The filtering mechanisms will be deployed in the exhausting chamber in order to lower the emissions of $\mathrm{CO}_{2}$ in the atmosphere. By enforcing this, windowless planes would be contributing a fraction in sustainable development. Sooner, these fractions will make a huge contribution in environment sustainability.

\subsection{Allows flexibility in designing or beautify the interior}

The numerous digital designs can be uploaded on screen display and thus giving a stunning interior to the plane.

\subsection{Enhances passenger relaxation}

Adjustable seats and use of organic led displays that eliminates the dependency on viewing angle and light orientation enhances the passenger relaxation and comfort. Moreover, it creates the illusion of being floating in air.

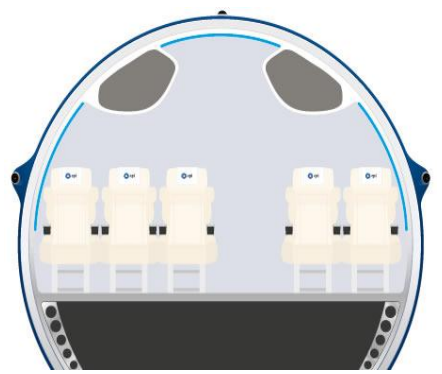

Fig. 4: Cross-sectional view of panoramic view [8]

Fig. 4 represents the inner cross-sectional view of screen arrangement as well seats management for displaying large panoramic views. Fig. 5 presents the rough model of outlooks of windowless airplane. Outer looks may not be able to give a distinguishable identity between a cargo planes or passenger plane but the features installed inside are making it always preferable choice for the passengers to board this only. Amorphous solar panels can be visualized on the plane's surface and rest all the inner features are being explained in fig. 1 \& fig. 2 under the section 2.

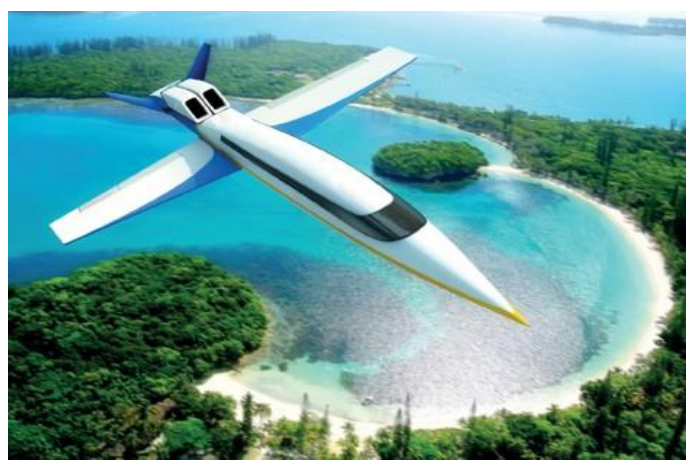

Fig.5: Outer view of Windowless Airplane [6] 


\section{Conclusions}

Windowless airplane is a complete novel modification for the airplane industry which is cost- effective, easy to use, reliable and robust. The concept of window substitution with the organic led displays is fundamentally revolutionary that sets a landmark in the extents of level of entertainment and proves that science is able to predict and invent any flight of imagination. The most astonishing fact is that all this is going to be done not with any sort of tradeoff between technology and efficiency and rather, the efforts have been made in order to derive a proportional relation between positive parameters and inversely proportional to that of cost and fuel consumption. This concept will take approximately 10 to 15 years in its execution and the challenge is to provide optimum performance and high flexibility of OLED screens.

\section{References}

[1] Trinaa Prasad, "Fasten Your Seatbelts. The Windowless Plane of the Future Will be a Mile-High Thrill," , in NDTV on 28 October 2014.

[2] Bernard Geffroy, Philippe le Roy and Christophe Prat review paper, "Organic light-emitting diode (OLED) technology: materials, devices and display technologies," Polym International 55:572-582 (2006) DOI: $10.1002 /$ pi.1974.

[3] CHUNG-SHENG LI AND WANJIUN LIAO “SOFTWARE DEFINED NETWORKS”, IEEE explore, guest editorial, IEEE Communications Magazine, February 2013.

[4] Kunic,S. Croatian Radiotelevision. HRT. 7agreh. Croatia, "OLED Technology and Displays," [IEEE, ISSN: 1334-2630, pp. 31-35, ELMAR, 2012 Proceedings].

[5] CPI, "WindowlessFuselage,"in The Telegraph.

[6] Ed Mazza, "Windowless Airplanes Of The Future Look Exciting... And Terrifying," in The Huffington Post in associationof Times Of India Group.

[7] Guo-Jiao Lv, Sch. of Electron. \& Inf. Eng., Sichuan Univ., Chengdu, China „ "Polarizer Parallax Barrier 3D Disnlav With High Brightness. Resolution and Low Crosstalk," IEEE vol. 10, issue 2, pp. 120-124, 16 October 2013 [Display Technology, Journal of vol.10, issue 2].

[8] Xin Zhao, Josep M. Guerrero, Xiaohua Wu, "Review of Aircraft Electric Power Systems and Architectures," in Proc. IEEE International Energy Conference (EnergyCon’14), 2014.

[9] Jost Weinmiller, "Grouping Wireless Picocells with a Distributed System," unpublished.

[10] Gonzo, L. , Ricerca Sci. e Tecnologica, Trento, Italy “Smart sensors for 3D digitization,”IEEE vol.1. Page(s): 117 - 122 vol.1 ISSN :1091-5281 [Instrumentation and Measurement Technology Conference, 2001. IMTC 2001. Proceedings of the 18th IEEE (Volume:1 )]. 